\title{
Laser injury of peripheral nerve: a model for focal endoneurial damage
}

\author{
ROBERT R MYERS, HECTOR E JAMES, HENRY C POWELL
}

From the Departments of Neurosciences, Anesthesiology, Surgery (Neurosurgery), and Pathology (Neuropathology), University of California, San Diego and the Veterans Administration Medical Center, San Diego, California, USA

SUMMARY A model of endoneurial oedema is presented which produces localised nerve fibre injury including Wallerian degeneration, endoneurial oedema and increased endoneurial fluid pressure. A carbon dioxide laser was used to irradiate rat sciatic nerve and quantitative results were collected 2 days and 6 days after irradiation. The increase in endoneurial fluid pressure is compared with other models of Wallerian degeneration in which the entire fascicle was involved to aid in a comparative study of the role of oedema in neuropathy.

A lesion produced by the laser is one of several models of endoneurial damage associated with Wallerian degeneration (table). The severity of the lesion is influenced by the frequency, energy density and duration of irradiation as well as the absorption coefficients of the tissue. Carbon dioxide laser irradiation of nervous system tissue produces localised lesions characterised histologically by a concentric zone of coagulation necrosis surrounded by persistent nerve oedema. ${ }^{2}$ In this paper we report the use of a carbon dioxide laser as a model of nerve injury which produces focal nerve fibre damage including Wallerian degeneration and axonal dystrophy, endoneurial oedema, and increased endoneurial fluid pressure.

Peripheral nerve fibres are maintained in a unique microenvironment ${ }^{3}$ created by the selective permeability characteristics of the vasa nervorum and the perineurial membrane which encloses fibres in discrete fascicles. Since the perineurium also has semi-elastic biomechanical properties, ${ }^{4}$ endoneurial

Table Endoneurial oedema and increased EFP associated with Wallerian degeneration and lesions of the axon

\footnotetext{
1. Traumatic injuries (crush)

2. Cold injury (cryoprobe)

3 . Chemical injury (compound $48 / 80$ )

4. Heat injury (laser)

5. Entrapment neuropathy (compression)
}

Address for reprint requests: Robert R. Myers, Ph.D., Anesthesia Research V-151, University of California, San Diego La Jolla, CA 92093, USA.

Received 12 February 1985. Accepted 22 April 1985 (interstitial) oedema can result in the elevation of endoneurial fluid pressure. The relationship between endoneurial hydration and tissue fluid pressure is important because increased pressure can lead to ischaemia and nerve fibre injury. In models of nerve oedema which have been studied previously, the entire fascicle has been involved. The purpose of studying the laser injury was to evaluate the severity of oedema in a lesion which affected only part of the fascicle.

\section{Methods}

Thirteen experimental and two control Sprague-Dawley rats (weight $200-250 \mathrm{~g}$ ) were used in this study. Animals were anaesthetised with an intraperitoneal injection of a solution containing sodium pentobarbitol (Nembutol, 50 $\mathrm{mg} / \mathrm{ml}$ ), saline, and diazepam (Valium, $5 \mathrm{mg} / \mathrm{ml}$ ) in volume proportions of 1:1:2. Sciatic nerves were exposed bilaterally by lateral incision of the thigh and reflection of the superficial muscle and fascia layers. Special care was taken to avoid damaging the nerves; the epineurium was left intact. This procedure resulted in exposure of the sciatic nerves and its branches for approximately $2 \mathrm{~cm}$ distal to the sciatic notch. An Advanced Biomedical Instruments Biolas 40 carbon dioxide laser with a beam diameter of 0.5 $\mathrm{mm}$, defocused to $2 \mathrm{~mm}$, was operated in the continuous wave mode at an output energy level of 5 watts to irradiate each sciatic nerve for a duration of 0.25 seconds $(n=12)$ or 0.5 seconds $(n=14)$. The lesion site was at the same level in each nerve, $1 \mathrm{~cm}$ distal to the sciatic notch in the most superficial fascicle. The lesion site was marked in the adjacent muscle by a single suture of 4-0 silk. Control animals received a sham operation. The muscle was approximated with interrupted 3-0 sutures and the skin wound closed with metal clips. Animals remained in an 
approved animal care facility until tissue was removed for pathologic examination at 48 hours or 6 days after irradiation.

In nerves irradiated for 0.5 seconds, endoneurial fluid pressure was measured by a micropipette technique in three nerves 48 hours after lesioning and in three nerves 6 days after lesioning. The method has been described previously $^{5}$ and is based on the impedance of a $4 \mu \mathrm{m}$-tipdiameter glass micropipette inserted directly into the subperineurial space of the nerve. Endoneurial fluid pressure can be recorded immediately thereafter by coupling changes in micropipette impedance to a servo-null, mechanical-electrical system which records hydraulic pressure equivalent to endoneurial fluid pressure. This technique produces minimal trauma to the nerve and permits repeated measurements in the same nerve or fascicle.

Sciatic nerves were removed under sodium pentobarbitol anaesthesia and immersed in $2.5 \%$ phosphatebuffered gluteraldehyde for 24 hours. Thereafter the tissue was post-fixed in osmium tetroxide followed by dehydration in serial alcohols and embedded in Araldite. One-micron-thick sections were stained with paraphenylenediamine for light microscopic analysis. Thin sections for electron microscopy were stained with uranyl acetate and lead citrate and examined in a Siemens Elmiscope 101 (Siemens Corporation, W. Berlin, FRG).

\section{Results}

Perivascular and subperineurial oedema was present in damaged areas, and often spread throughout the fascicle (fig 1). The severity of the lesion related directly to the laser energy delivered; some nerve fascicles were spared while others were completely involved. In most cases, the major fascicle was only partially damaged. In nerves irradiated for $0.5 \mathrm{sec}-$ onds, endoneurol fluid pressure (EFP) averaged $7 \cdot 4$ $\pm 0.8 \mathrm{cmH}_{2} \mathrm{O} 48$ hours after irradiation; by 6 days

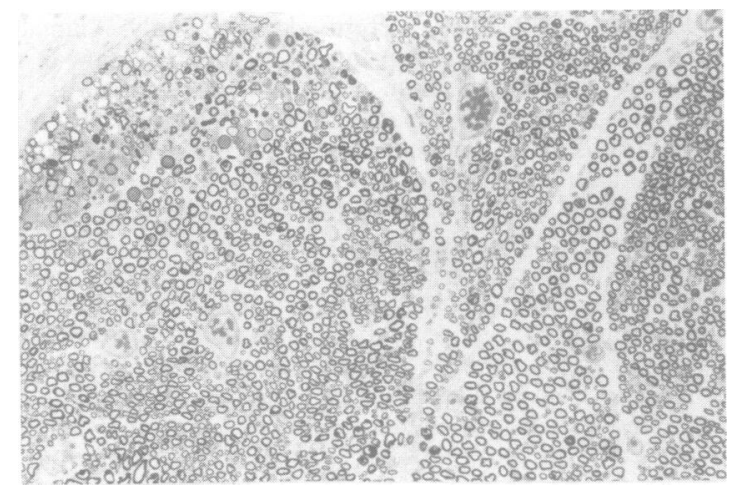

Fig 1 Light micrograph of rat sciatic nerve 48 hours after irradiation with a carbon dioxide laser, 5 watts, 0.25 seconds. Note localised nerve fibre damage in upper left and extensive endoneurial oedema in perivascular spaces and separating nerve fibres. Paraphenylene diamine stain with original magnification $(\times 100)$. the EFP had fallen to an average value of $4.9 \pm 0.9$ $\mathrm{cmH}_{2} \mathrm{O}$. When tested with Student's one-tailed $t$ test, both experimental values were significantly different $(p<0.025)$ from control EFP of $2.0 \pm 1.0$ $\mathrm{cmH}_{2} \mathrm{O}$ and from each other.

Sections of laser-injured nerves showed discrete endoneurial lesions characterised by nerve fibres undergoing Wallerian degeneration, as well as endoneurial oedema (fig 1). Affected fibres showed massive swelling with darkly stained axoplasm and attenuated myelin sheaths (fig 2). Unmyelinated nerve fibres were similarly affected. No inflammatory changes were noted. The endoneurial interstitium also showed cells undergoing bubbly disintegration.

Electron microscopy showed greatly swollen

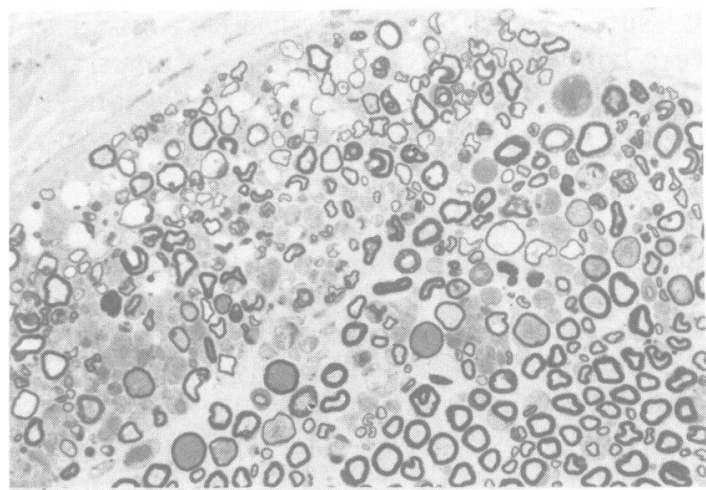

Fig 2 Higher power light micrograph of localised lesion with carbon dioxide laser, 5 watts, $0 \cdot 25$ seconds. Note Wallerian degeneration in this tissue 48 hours after irradiation. There is massive swelling of affected fibres with darkly stained axoplasm and attenuated myelin sheaths. Paraphenylene diamine, $(\times 250)$.

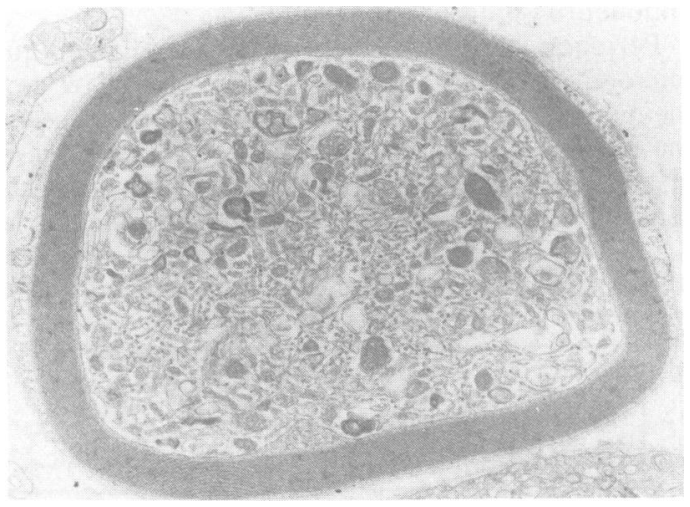

Fig 3 Electron micrograph of swollen axon 48 hours after being irradiated with carbon dioxide laser, 5 watts, 0.25 seconds. Axoplasm is packed with organelles including large numbers of mitochondria and membrane-bound bodies. Lead citrate $(\times 8000)$. 
axons packed with organelles (fig 3 ) including large numbers of mitochondria and membrane-bound dense bodies. The changes observed were characteristic of axonal dystrophy during acute Wallerian degeneration.

\section{Discussion}

In this model, a localised injury is produced which is characterised by Wallerian degeneration, endoneurial oedema, and increased endoneurial fluid pressure. Individually, these are characteristics of many neuropathies due to physical agents ${ }^{6}$ such as those listed in the table although they are combined in this model within a localised area superficially in a single fascicle. Laser injuries are produced through heating of the tissue ${ }^{78}$ with some cellular structures being damaged more than others owing to increased absorption of heat energy. Although the absorption coefficients of nervous system tissue are not completely known, ${ }^{9}$ myelin may be more susceptible to damage by heat energy since there is vacuolation of myelin in thermal injuries. ${ }^{7}$ The explosive vaporisation of surface tissue produces severe damage including vascular disruption and coagulation. The associated secondary ischaemia may compound the injury. ${ }^{10}$

The role of oedema in the compartmentalised central nervous system tissue is recognised to be pathogenic since it is associated with ischaemia. Because it is sharply localised, the laser-induced lesion has been used to model brain oedema" with little disruption of the blood-brain barrier surrounding the lesion. ${ }^{12}$ For this reason the laser injury is of particular interest in peripheral nerve; Lele has reported that the perineurium is apparently unaffected in heat-induced injuries to peripheral nerves. ${ }^{7}$ In ophthalamic surgery, increased intraocular pressure has been associated with laser trabeculoplasty ${ }^{13}$ while in the present study laser injury is associated with increased endoneurial fluid pressure. The relationship between endoneurial oedema and endoneurial fluid pressure in peripheral nerve is triphasic: after small volumes of oedema occupy the limited potential space within the endoneurium, additional fluid accumulation is directly related to elevations in EFP until the perineurium is damaged and its permeability characteristics are altered. ${ }^{14}$ Early changes in nerve hydration affect the ionic homeostasis of the endoneurial environment ${ }^{14}$ and can be manifested clinically in electrophysiological dysfunction while chronic endoneurial oedema is associated with significant structural change of nerve fibres. ${ }^{15}$ This is thought to occur by way of a secondary ischaemic mechanism caused by compression of nutritive vessels which traverse the perineurium and are vulnerable to perineurial stretching. Evidence for this hypothesis comes from biomechanical computer modeling of nutrient vessels traversing the perineurium ${ }^{16}$ and from the association between increased EFP and reduced nerve blood flow which has recently been reported in two oedematous neuropathies. ${ }^{17} 18$ Oedema and increased endoneurial fluid pressures are dynamic phenomena in peripheral nerve injuries. In Wallerian degeneration caused by crush injury ${ }^{19}$ oedema is present following the traumatic injury but EFP gradually rises to peak on the sixth day after injury after which it is slowly reduced to normal values during the next 30 days of nerve regeneration. This late peak in EFP is thought to be due to the superposition of EFP changes caused by the initial vascular injury and later changes affected by the proliferation of Schwann cells and alterations in permeability associated with liberated vasoactive amines and myelin digestion. When nerves are locally frozen with a cryoprobe ${ }^{20}$ Wallerian degeneration is also observed although EFP reaches a peak of approximately $20, \mathrm{cmH}_{2} \mathrm{O}$ within 90 minutes after freezing owing to extensive initial vascular damage; a second, smaller, peak in EFP at 6 days after freezing has been ascribed to the Wallerian degeneration process. EFP changes in laser-induced injuries are intermediate between these other two models: EFP is initially high but persists during the process of Wallerian degeneration. These effects are moderated by the limited extent of the lesion and would be expected to be similar in magnitude to those reported in freeze lesions if the injuries were more extensive. The ability to finely control the severity of laser-induced lesions in peripheral nerve by varying the incident energy density and duration of exposure represents an important addition to the various models of endoneurial oedema used to study the biophysics of the perineurium and the role of the endoneurial environment in the pathogenesis of nerve injury and regeneration.

Supported by the Veterans Administration Research Service and NIH Grants NS18715 and NS14162.

\section{References}

' Boggan JE, Edwards MSB, Davis RL, Bolger CA, Martin N. Comparison of the brain tissue response in rats to injury by argon and carbon dioxide lasers. Neurosurgery 1982;11:609-16.

${ }^{2}$ Edwards MSB, Boggan JE, Fuller TA. The laser in neurological surgery. J Neurosurg 1983;59:555-66.

${ }^{3}$ Myers RR, Heckman HM, Powell HC. Endoneurial fluid is hypertonic. Results of microanalysis and 
significance in neuropathy. $J$ Neuropathol Exp Neurol 1983;42:217-24.

${ }^{4}$ Ross MH, Reith EJ. Perineurium: Evidence for contractile elements. Science 1969;165:604-6.

${ }^{5}$ Myers RR, Powell HC, Costello ML, Lampert PW, Zweifach BW. Endoneurial fluid pressure: Direct measurement with micropipettes. Brain Res 1978; 148:510-5.

- Thomas PK, Holdorff B. Neuropathy due to physical agents. In: Dyck PJ, Thomas PK, Lambert EH, Bunge R, eds. Peripheral Neuropathy, Vol. II. Philadelphia: WB Saunders, 1984:1479-511.

${ }^{7}$ Lele PP. Effect of focused ultrasonic radiation on peripheral nerve, with observations on local heating. Exp Neurol 1963;8:47-83.

${ }^{8}$ Lombard GF, Benech F, Tealdi S, Ponzio RM. Thermal effects on nervous human tissues under electro or laser surgery. J Neurosurg Sci 1982;26:265-71.

${ }^{9}$ Svaasand LO, Ellingson R. Optical properties of human brain. Photochem Photobiol 1983;38:293-99.

${ }^{10}$ Daube JR, Dyck PJ. Neuropathy due to peripheral vascular diseases. In: Dyck PJ, Thomas PK, Lambert EH, Bunge R, eds, Peripheral Neuropathy, Vol. II. Philadelphia: WB Saunders, 1984:1458-78.

"Benson VM, McLaurin RL, Foulkes EC. Traumatic cerebral edema. An experimental model with evaluation of dexamethasone. Arch Neurol 1970;23:17986.

12 Toya S, Kawasa T, Iisaka Y, et al. Acute effect of the carbon dioxide laser on the epicerebral microcircu- lation. Experimental study by fluorescein angiography. J Neurosurg 1980;53:193-7.

${ }^{13}$ Weinreb RN, Ruderman J, Juster R, Zweig K. Immediate intraocular pressure response to argon laser trabeculoplasty. Am J Ophthalmol 1983;95:279-86.

${ }^{14}$ Myers RR, Powell HC, Shapiro HM, Costello ML, Lampert PW. Changes in endoneurial fluid pressure, permeability, and peripheral nerve ultrastructure in experimental lead neuropathy. Ann Neurol 1980;8:392-401.

15 Powell HC, Myers RR, Schwann cell changes and demyelination in chronic galactose neuropathy. Muscle Nerve 1983;6:218-27.

${ }^{16}$ Myers RR. Microvascular compression of nutritive vessels in oedematous neuropathies. Microvasc Res 1985;29: 242.

${ }^{17}$ Myers RR, Mizisin AP, Powell HC, Lampert PW. Reduced nerve blood flow in hexachlorophene neuropathy. Relationship to elevated endoneurial fluid pressure. J Neuropathol Exp Neurol 1982; 41:391-99.

${ }^{18}$ Myers RR, Powell HC. Reduced nerve blood flow in galactosemic neuropathy. Ann Neurol 1984;16:58794.

19 Powell HC, Myers RR, Costello ML, Lampert PW. Endoneurial fluid pressure in Wallerian degeneration. Ann Neurol 1979;5:550-7.

${ }^{20}$ Myers RR, Powell HC, Heckman HM, Costello ML, Katz J. Biophysical and pathological effects of cryogenic nerve injury. Ann Neurol 1981;10:478-85. 